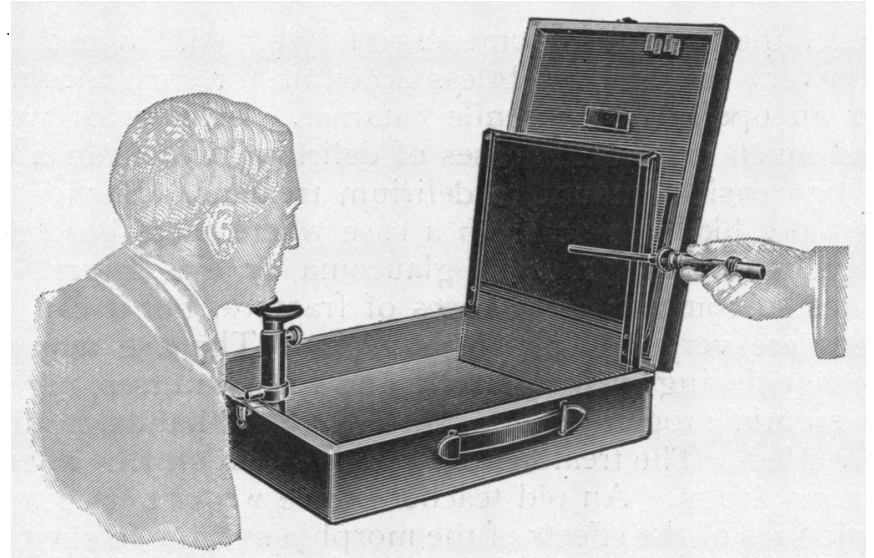

As soon as the patient says that the light has gone, a slight pressure on the chart with the rod will bring the pin point into action and a prick will be made on the chart. After the scotometer has been adequately " pricked" the chart is removed and reversed. A line is then drawn in the usual manner joining the pin pricks.

The advantages of this method of charting are that the patient's attention is not diverted by any shining points on the surface of the carrier of the "moving spot" nor by the operator's hand. Also it avoids the difficulty of even illumination of the chart itself. The chart having a matt black surfare presented to the patient conceals the moving rod sufficiently to concentrate his attention on the spot of light. The instrument works well in a subdued light and a completely dark room is unnecessary. The bulbs and battery are of the ordinary pocket torch type. The eye that is not being examined may be totally occluded, or a trial frame may be used with a stenopaeic disc of small aperture allowing this eve to see the fixation spot only. The use of a stenopaeic disc allows both eyes to fix on the central spot, and so has many advantages.

I have used this scotometer for about eighteen months and have found it successful.

\title{
ANNOTATION
}

\section{Post-operative Delirium}

Among the rarer sequelae of ophthalmic operations may occur post-operative delirium. As a rule, in the aged, this is of low degree and does not go much beyond muttering and picking 
at the bedclothes. The irksomeness of lying still in bed in one $\frac{0}{3}$ position is very real and doubtless accounts for such a complication after an operation for senile cataract. In contrast we may $\vec{F}$ rarely find much more acute cases of delirium, which, in a heavy drinker, may easily amount to delirium tremens. Such a catas-등 trophe is more likely to occur in a case where there has been an $\bar{c}$. emergency operation for acute glaucoma or eye injury. It is $\stackrel{\square}{\square}$ not perhaps so common as in cases of fracture, but it can occur. Such cases are very difficult to manage. The eye may easily suffer damage during such an attack, and special nurses, night and day, are essential ; together with shackles for the hands, if mischief $\vec{\omega}$ is to be avoided. The treatment of the delirium may be attempted $\frac{\mathscr{O}}{\sigma}$ by numerous drugs. An old teacher of the writer's used to drawo. gloomy pictures of the effects of the morphia syringe in such cases, $\stackrel{\sim}{\circ}$ and adjure us to pin our faith to full doses of bromides in goodo stout.

Paraldehyde will probably subdue the condition as quickly aso anything ; and one of the most important points in treatment is toinduce sleep at almost any cost.

If all else fails we may remember the story told by Dean Ramsayc in his "Reminiscences of Scottish Life and Character," where a nobleman was very ill and unable to sleep. His physicians weseco in perplexity as they considered that, unless sleep could beo obtained, there was little chance of recovery. The son of the house, who had always been considered a little daft was with hearing of the consultation and suddenly called out " Sen' for thato preachin' man frae Livingstone, for faither aye sleeps in theő kirk." This advice was acted on with excellent results !

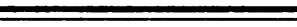 \\ ABSTRACTS \\ MISCELLANEOUS}

(1) Nixon, J. A. (Bristol).-Bristol Eye Hospital. The Bristo Medico-Chirurgical Journal, Vol. LIII, April, 1936.

(1) As is well known Bristol stands third in order of foundation among the English eye hospitals. It was founded in 1810, and is only preceded by Moorfields, 1804, and Exeter, 1808.

W. H. Goldwyer, of a well known Bristol medical family, was the prime mover of the foundation, which met with such success 